peutic effects of both regimens were comparable. They argued both from an analysis of published deaths attributed to methotrexate and also from experimental pharmacological data that toxicity was less with large intermittent dosage though the data did not specifically relate to hepatotoxicity. Nevertheless, Baker (1970) reported major side effects in 5 out of 18 patients treated in this way.

Although the toxicity of methotrexate makes it a far from ideal treatment for psoriasis it remains of great value in very severe forms of this disease. Our findings indicate that a regimen of intermittent large dosage is safer in these circumstances if treatment is prolonged.

We thank the dermatologists of the Royal Victoria Infirmary, Newcastle upon Tyne, St. John's Hospital for Diseases of the Skin, the London Hospital, and the Royal Free Hospital for allowing us to study patients under their care. We are also grateful for help from the departments of pathology in these hospitals. Professor Sam Shuster has provided much helpful criticism and advice.

M.G.C.D. is in receipt of a Medical Research Council Junior Research Fellowship.

Requests for reprints should be addressed to Dr. M. G. C. Dahl.

\section{References}

Almeyda, J., Barnardo, D., and Baker, H. (1971). British fournal of Dermatology, 85, 302 .

Baker, H. (1970). British fournal of Dermatology, 82, 65

Coe, R. O., and Bull, F. E. (1968). Fournal of the American Medical Associa-

tion, 206, 1515.
Colsky, J., Greenspan, E. M., and Warren, T. N. (1955). Archives of Patho$\log y, 59,198$.

Dahl, M. G. C., Gregory, M. M., and Scheuer, P. J. (1971). British Medical fournal, 1, 625.

Dubin, H. V., and Harrell, E. R. (1970). Archives of Dermatology, 102, 498. Epstein, E. H., and Croft, J. D. (1969). Archives of Dermatology, 100, 531 Hersh, E. M., Wong, V. G., Henderson, E. S., and Freireich, E. J. (1966). Cancer (Philadelphia), 19, 600.

Hutter, R. V. P., Shipkey, F. H., Tan, C. T. C., Murphy, M. L., and Chowdhury, M. (1960). Cancer (Philadelphia), 13, 288.

McDonald, C. J., and Bertino, J. R. (1968). Lancet, 1, 864.

Menghini, G. (1958). Gastroenterology, 35, 190.
Muller, S. A., Farrow, G. M., and Martalock, D. L. (1969). Archives of Dermatology, 100, 523.

O'Rourke, R. A., and Eckert, G. E. (1964). Archives of Internal Medicine, 113, 191

Rees, R. B., Bennett, J. H., Maibach, H. I., and Arnold, H. L. (1967). Archives of Dermatology, 95, 2.

Sharp, H., Nesbit, M., White, J., and Krivit, W. (1969). Fournal of Pediatrics, $74,818$.

Taft, L. I. (1965). Israel fournal of Medical Sciences, 1, 823.

Weinstein, G. D., et al. (1970). Archives of Dermatology, 102, 613.

Zachariae, H., and Schiфdt, T. (1971). Acta Dermato-venereologica, 51, 215.

\title{
Diabetic Amyotrophy: A Follow-up Study
}

\author{
E. B. CASEY, M. J. G. HARRISON
}

British Medical fournal, 1972, 1, 656-659

\section{Summary}

A clinical follow-up study of 12 patients with diabetic amyotrophy is reported. Re-examination after an interval indicated that improvement had occurred in all but one instance, and had been maintained over an average follow-up period of four and a half years. Improvement in the neurological syndrome appeared to follow improvement in diabetic control or institution of treatment in those whose diabetes had not previously been diagnosed.

Seven patients made a good functional recovery, three no longer having any muscular weakness. Five showed significant residual disability.

\section{Introduction}

The commonest form of diabetic neuropathy is a symmetrical sensory disturbance in the lower limbs with depression or loss of tendon reflexes (Goodman, Frankel, Baumoel, Marcus, and Wassermann, 1953; Fry, Hardwick, and Scott, 1962).

Garland and Taverner (1953) described an asymmetrical motor syndrome occurring in elderly subjects in which wasting and weakness principally affected proximal muscles in the legs. Sullivan (1958) described cases of both types, and contrasted the two clinical syndromes. Garland $(1955,1960)$ noted that the motor syndrome, which he called diabetic amyotrophy, tended to recover if good diabetic control was established, and this has been the general experience (Fry et al., 1962; Redwood, 1962;

\footnotetext{
Department of Rheumatology and Physical Medicine, the Middlesex Hospital, London W.1

E. B. CASEY, M.D., M.R.C.P., Senior Registrar

The National Hospital,Queen Square, London W.C.1

M. J. G. HARRISON, D.M., M.R.C.P., Senior Registrar
}

Gilliatt, 1965; Hamilton, Dobson, and Marshall, 1968). Few reports, however, have dealt particularly with the natural history of diabetic amyotrophy. We thought a long-term clinical follow-up study of a group of patients with diabetic amyotrophy would be of interest.

\section{Methods}

Fourteen patients had been diagnosed in the neurological department of the Middlesex Hospital or at the National Hospital, Queen Square, between 1958 and 1968 as suffering from diabetic amyotrophy as described by Garland. One died of carcinomatosis and one moved abroad. The remaining 12 were traced and studied. Information was sought from the hospital records about the duration and severity of the diabetes mellitus before the development of the neurological syndrome, and about the presenting symptoms and degree of functional disability.

All the patients were re-examined by one or both of us. We asked them about the control of their diabetes and their neurological symptoms, and compared our findings on clinical examination with those recorded at the time of diagnosis. Diabetic clinic notes gave additional information on the degree of diabetic control. This was considered "poor" if glycosuria or random blood sugar levels of over $200 \mathrm{mg} / 100 \mathrm{ml}$ had occurred frequently, "fair" if glycosuria occurred only occasionally, and "good" if glycosuria was rare and no random blood sugar levels had been over $200 \mathrm{mg} / 100 \mathrm{ml}$.

The follow-up period ranged from 10 months to 12 years. The results are presented in summarized form and illustrative case histories are given. Three of the cases have been reported before. Cases 1 and 10 were briefly described by Gilliatt (1965) and Case 9 by Gilliatt and Willison (1962, Case 7).

\section{Clinical Data}

The 12 patients (nine men and three women) were aged 51 to 72 (mean 63) years at the time of the diagnosis of diabetic 
TABLE I-Distribution of Wasting and/or Weakness

\begin{tabular}{|c|c|c|c|c|c|c|c|c|c|c|c|c|c|}
\hline $\begin{array}{l}\text { Case } \\
\text { No. }\end{array}$ & $\begin{array}{c}\text { Hospital } \\
\text { No. }\end{array}$ & Sex & Age & Shoulder & $\begin{array}{l}\text { Upper } \\
\text { Arm }\end{array}$ & Forearm & Hand & $\underset{\text { Flexion }}{\text { Hip }}$ & $\underset{\text { Extension }}{\text { Hip }}$ & Quadriceps & $\begin{array}{l}\text { Ham- } \\
\text { strings }\end{array}$ & $\begin{array}{l}\text { Tibialis } \\
\text { Anterior }\end{array}$ & Calf \\
\hline $\begin{array}{r}1^{*} \\
2^{*} \\
3 \dagger \\
4 \dagger \\
5 \dagger \\
6^{*} \\
7 \dagger \\
8^{*} \\
9^{*} \\
10 \dagger \\
11+ \\
12 \dagger\end{array}$ & $\begin{array}{r}\text { K88374 } \\
\text { H37638 } \\
\text { A10124 } \\
\text { A } 3489 \\
65224 \\
\text { G92077 } \\
37618 \\
\text { G53680 } \\
\text { K75540 } \\
78351 \\
\text { A36980 } \\
\text { A23199 }\end{array}$ & $\begin{array}{l}\text { F. } \\
M . \\
M . \\
M . \\
M . \\
M . \\
F . \\
M . \\
M . \\
F \\
M \\
M\end{array}$ & $\begin{array}{l}65 \\
72 \\
67 \\
67 \\
67 \\
52 \\
61 \\
67 \\
62 \\
60 \\
66 \\
51\end{array}$ & $\begin{array}{l}0 \\
0 \\
++ \\
0 \\
0 \\
0 \\
0 \\
0 \\
+ \\
0 \\
+ \\
+\end{array}$ & $\begin{array}{l}0 \\
+\quad+ \\
0 \\
0 \\
0 \\
0 \\
0 \\
0 \\
0 \\
0 \\
0 \\
0\end{array}$ & $\begin{array}{l}\mathbf{0} \\
\mathbf{0} \\
\mathbf{0} \\
\mathbf{0} \\
\mathbf{0} \\
\mathbf{0} \\
\mathbf{0} \\
\mathbf{0} \\
\mathbf{0} \\
\mathbf{0} \\
\mathbf{0} \\
+\end{array}$ & $\begin{array}{l}0 \\
+ \\
0 \\
+ \\
0 \\
0 \\
0 \\
+ \\
0 \\
0 \\
+ \\
+\end{array}$ & $\begin{array}{c}t+t \\
++ \\
+t \\
+t \\
++ \\
+t \\
t++ \\
+ \\
++ \\
++ \\
++\end{array}$ & $\begin{array}{l}t \\
++ \\
++ \\
++ \\
++ \\
+t \\
++ \\
+ \\
0 \\
++ \\
+t\end{array}$ & $\begin{array}{c}+++ \\
++ \\
++ \\
+++ \\
++ \\
++ \\
+++ \\
++ \\
++ \\
++ \\
++ \\
++\end{array}$ & $\begin{array}{l}+++ \\
++ \\
+++ \\
++ \\
++ \\
++ \\
++ \\
++ \\
++ \\
++ \\
++ \\
++\end{array}$ & $\begin{array}{c}+ \\
++ \\
+++ \\
++ \\
+ \\
+ \\
+ \\
++ \\
+ \\
+ \\
++ \\
++\end{array}$ & $\begin{array}{c}+ \\
++ \\
+ \\
++ \\
+ \\
+ \\
0 \\
++ \\
+ \\
+ \\
++ \\
++\end{array}$ \\
\hline
\end{tabular}

* Middlesex Hospital.

† Middlesex Hospital.

Degree of wasting and/or weakness (in the more affected limb): $0=$ none, $i=$ mild, $+t=$ moderate, $+t+=$ severe.

amyotrophy. Eight had been diagnosed as suffering from diabetes mellitus six months to 12 years previously. The diabetes was considered to have been mild in five and moderately severe in only three. Three of the patients had received insulin and one an oral hypoglycaemic agent.

Diabetic control was adjudged to have been poor in two, fair in three, and good in two. One patient with mild diabetes had received no treatment. Four patients were found to be diabetic only when they were referred for neurological investigation.

All but one of the patients had complained of pain in the legs and this had often been severe, particularly at night. All had noted weakness of one or both legs. Six were unable to walk without mechanical aids or support, and one was unable to stand. Five had repeated falls. Ten patients had mild sensory symptoms.

Examination had shown muscle wasting and weakness in the lower limbs in all. The wasting was usually most pronounced in the quadriceps. Distal limb muscles were less frequently affected by wasting. Spontaneous fasciculation was seen in four patients (including one with a previous history of poliomyelitis). All had asymmetrical weakness in the legs affecting principally hip flexion and knee extension. Three also had a severe footdrop. Tendon jerks in the lower limbs were depressed or absent in all 12 patients. Extensor plantar responses were recorded in two. In neither case could this be attributed to gross weakness of plantar flexion of the big toe.

Weakness and wasting in the upper limbs were noted in seven patients but were less severe than in the lower limbs. The distribution of muscle wasting and weakness is shown in Table I.

Sensory changes were those of a symmetrical distal neuropathy in the lower limbs in six patients. In two patients sensory impairment was unilateral (in one this followed the distribution of a lateral popliteal nerve lesion). In two others the only abnormality was impairment of vibration sense, which was of doubtful significance because of their age. Two patients had no sensory abnormality. In view of the severe wasting and weakness of the quadriceps muscle in many of the patients (Table I), it is of interest that none had a distribution of sensory loss which definitely pointed to a lesion of the femoral nerve trunk.

The cerebrospinal fluid protein was raised in six cases, reaching a level of $200 \mathrm{mg} / 100 \mathrm{ml}$ in three.

Electrodiagnostic studies had been performed in all 12 cases. Muscle sampling in the lower limbs (in nine cases) revealed the presence of sustained fibrillation in six and a severely reduced interference pattern in three. In none were the changes of a myopathic process seen. Motor conduction velocity was measured in the lateral or medial popliteal nerves in nine patients and marked reduction was found in three (Table II). The femoral nerve was inexcitable in one patient.

No ascending nerve action potential could be recorded from the lateral popliteal nerve in five patients. In one patient (Case 12) a normal nerve action potential was recorded (Table II).
TABLE II-Electrodiagnostic Studies (Lower Limb)

\begin{tabular}{|c|c|c|c|}
\hline $\begin{array}{c}\text { Case } \\
\text { No. }\end{array}$ & Muscle & $\begin{array}{l}\text { Motor Conduction } \\
\text { Velocity } \\
(\mathrm{m} / \mathrm{sec})\end{array}$ & $\begin{array}{l}\text { Lateral Popliteal } \\
\text { Ascending Nerve } \\
\text { Action Potential } \\
(\mu \mathrm{V})\end{array}$ \\
\hline $\begin{array}{r}1 \\
3 \\
4 \\
5 \\
6 \\
7 \\
8 \\
9 \\
11 \\
12 \\
\text { Normal }\end{array}$ & $\begin{array}{l}\text { Extensor digitorum brevis } \\
\text { Extensor digitorum brevis } \\
\text { Extensor digitorum brevis } \\
\text { Extensor digitorum brevis } \\
\text { Extensor digitorum brevis } \\
\text { Abductor hallusis longus } \\
\text { Extensor digitorum brevis } \\
\text { Extensor digitorum brevis } \\
\text { Tibialis anterior } \\
\text { Extensor digitorum brevis }\end{array}$ & $\begin{array}{c}19 \\
36 \\
40 \\
29 \\
36 \\
31 \\
39 \\
25 \\
35 \\
35 \cdot 6-63 \cdot 5 \\
\text { Mean } 49 \cdot 7 \pm 7 \cdot 1^{*}\end{array}$ & $\begin{array}{c}0 \\
0 \\
0 \\
0 \\
\\
0 \\
8 \\
2-15 \cdot 5 \dagger\end{array}$ \\
\hline
\end{tabular}

* Thomas, Sears, and Gilliatt (1959).

Thomas, Sears, and Gilliatt (1959).
† Gilliatt, Goodman, and Willison (1961).

\section{Follow-up Assessment}

DIABETIC CONTROL

Treatment had been started for the four undiagnosed cases and for one patient whose mild diabetes had been diagnosed but not treated previously. Insulin had been added to the regimen in two cases and oral agents added in one other (Table III).

TABLE IH-Diabetic Treatment Given

\begin{tabular}{l|c|c|c|c}
\hline & \multicolumn{3}{|c|}{ Diabetic } & Treatment \\
\cline { 2 - 5 } & None & $\begin{array}{c}\text { Diet } \\
\text { Alone }\end{array}$ & $\begin{array}{c}\text { Oral } \\
\text { Agents }\end{array}$ & Insulin \\
\hline $\begin{array}{l}\text { Before neurological complication } \\
\text { After neurological complication }\end{array}$ & 5 & 3 & 1 & 3 \\
\hline
\end{tabular}

The subsequent control was assessed as having been poor in one patient, fair in one, and good in the remainder (Table IV).

TABLE IV-Diabetic Control before and after Appearance of Diabetic Amyotrophy (For Method of Assessment see Text)

\begin{tabular}{l|c|c|c|c}
\hline & \multicolumn{3}{|c|}{ Diabetic Control } \\
\cline { 2 - 4 } & $\begin{array}{c}\text { No } \\
\text { Treatment }\end{array}$ & Poor & Fair & Good \\
\hline $\begin{array}{l}\text { Before neurological complication } \\
\text { After neurological complication }\end{array}$ & 5 & 2 & 3 & 2 \\
\hline
\end{tabular}

\section{NEUROLOGICAL ASSESSMENT AT FOLLOW-UP}

Nine patients had lost their pain; this had subsided within a few months of the time of diagnosis. Two still had occasional aching 
in the thigh. All but one had noted functional improvement. Four still required mechanical aids for walking (calipers, sticks, etc.). Three considered the strength in their legs to have returned to normal.

Examination of the lower limbs showed persistent wasting in five patients only, and muscle strength had clearly improved in all but one (Case 4). Three patients had no weakness. In five patients tendon reflexes previously absent had returned. In one of the two patients with extensor plantar responses a flexor response was now obtained.

Sensory examination showed that improvement had occurred in five patients, including both of those with a unilateral disturbance. Two others with a mild distal neuropathy showed no change. One patient with no sensory signs initially had now lost vibration sense below the knees. In two patients (Cases 1 and 4) a marked progression of the symmetrical distal sensory impairment had occurred. In Case 1 this had occurred in spite of improvement in the motor syndrome and good diabetic control. The only patient who failed to regain muscle power or show functional recovery (Case 4) was also the patient in whom diabetic control had been particularly difficult.

In assessing progress recovery was considered to be good if there was little or no disability, fair if despite recovery significant disability persisted and if aids were still required for walking. If little or no recovery had occurred the result was recorded as poor. The following three case histories are presented to illustrate good, fair, and poor functional recoveries.

\section{Case 1}

The patient (M.H. K88374), a retired school matron aged 65, developed pneumonia and was admitted to her local hospital in coma. She was found to be diabetic and was treated with insulin zinc suspension. One month later she developed pain around the right knee and had difficulty climbing stairs. Over the coming months weakness of the right leg progressed and she became unable to walk unaided. Seven months after the onset of her neurological symptoms she was admitted to the Middlesex Hospital under the care of Professor Gilliatt

Examination showed wasting of both quadriceps (right greater than left). Fasciculation was seen in the tibialis anterior and calf on the right. She could only just raise her right leg off the bed, and there was moderate weakness of hip flexion on the left. Gross weakness of the quadriceps and hamstrings on the right was present, and mild weakness of these muscles on the left. Mild weakness of dorsiflexion and plantar flexion of the right foot were also found, power at the left ankle being normal. No tendon jerks could be obtained in the legs and the plantar responses were flexor. The only sensory abnormality was loss of vibration sense below the costal margin.

Electrical testing showed a greatly reduced interference pattern and the presence of denervation potentials in the right extensor digitorum brevis. Motor conduction velocity in the lateral popliteal nerve was $19 \mathrm{~m} / \mathrm{sec}$.

Although her diabetes seemed well controlled random blood sugars ranged from 146 to $212 \mathrm{mg} / 100 \mathrm{ml}$. Diabetic control was established with an increased dose of insulin (44 units in place of 28). Pain relief was obtained in four months and after 10 months she reported striking recovery.

At follow-up eight years later she was able to walk normally. She was aware of the return of the bulk of her thigh muscles. On examination there was no wasting and only slight weakness of hip flexion bilaterally. Her left knee jerk could just be elicited. Sensory testing showed, in addition to the loss of vibration sense, impairment to light touch and pin-prick in a stocking distribution below both knees. Her gait was normal.

Comment.-Muscle wasting and weakness developed shortly after the appearance of diabetes mellitus. Recovery occurred when diabetic control was achieved by reference to blood sugar levels. Distal sensory changes increased while the proximal motor syndrome recovered.

\section{Case 4}

The patient (N.H. A3489), a 67-year-old man, had been found to be diabetic five years previously but despite a combination of soluble insulin and P.Z.I. and phenformin his control had never been good. While in hospital elsewhere with chest pain he developed pain in the right thigh. At this time he was showing marked glycosuria and blood sugars of up to $331 \mathrm{mg} / 100 \mathrm{ml}$. The leg pain became severe and over the subsequent six months he developed weakness of the right leg with frequent falls and difficulty climbing stairs. He was admitted to the National Hospital in January 1967.

On examination there was slight wasting of the left hypothenar eminence but no other abnormality in the upper limbs. In the legs there was wasting of the glutei, quadriceps, and calf muscles bilaterally (right greater than left) with tenderness of the right quadriceps. There was weakness, particularly of the right quadriceps. The knee jerks were absent and the ankle jerks depressed. No plantar response was obtained. Sensory testing showed minimal joint position sense loss in the toes, absent vibration sense below the iliac crests, and occasional misses of light louch on the feet and tips of fingers of both hands.

Electrical testing showed denervation in the left quadriceps with sustained fibrillation. Motor conduction velocity in the left lateral popliteal nerve was $40 \mathrm{~m} / \mathrm{sec}$, and no ascending nerve action potential could be recorded. Sensory action potentials (Gilliatt and Sears, 1958) were reduced in amplitude in both ulnar and median nerves at the right wrist (ulnar $2 \mu \mathrm{V}$; median $7 \mu \mathrm{V}$ ). The cerebrospinal fluid contained $80 \mathrm{mg}$ of protein per $100 \mathrm{ml}$.

Diabetic control in the ward was adequate on the same treatment (only one blood sugar above $150 \mathrm{mg} / 100 \mathrm{ml}$ ) and his weakness perhaps improved though pain persisted.

Over the following eight months he noted no functional improvement. He was then readmitted to the Middlesex Hospital. He had gross wasting and almost complete loss of voluntary power in both legs. The lower limb reflexes were absent and the plantar responses flexor. There was a dense stocking anaesthesia and analgesia to the knees with complete loss of postural sensation in the toes. He had a mild left radial nerve (posterior interosseous) palsy.

His diabetic control in the ward on the treatment regimen of the previous eight months was poor with daily $2 \%$ glycosuria and blood sugars of up to $248 \mathrm{mg} / 100 \mathrm{ml}$. Control improved slightly with increased carbohydrate restriction and blood sugars then fell below $183 \mathrm{mg} / 100 \mathrm{ml}$. The insulin requirement was found to be twice that which he had received before admission.

He remained difficult to control and two years later was still able to walk only a step or two with a Zimmer frame.

Comment.-Diabetic amyotrophy developed in a poorly controlled diabetic. Control remained persistently poor during the follow-up period and there was no evidence of improvement in muscle wasting or weakness except perhaps during a brief period of adequate control during a hospital admission. Distal sensory loss increased during the follow-up period.

\section{Case 7}

The patient (N.H. 37618), a 61-year-old housewife; had been diabetic for 12 years, treated by diet alone. For two years before admission she had complained of pain in the left leg, particularly at night, and then over the course of three months she had developed progressively increasing weakness of both legs and had become confined to a chair. During this three-month period, and associated with the development of a gastric ulcer, her diabetes had become uncontrolled, and she had lost $28 \mathrm{lb}(12.7 \mathrm{~kg})$ in weight. It had been necessary to add chlorpropamide to her treatment.

On admission to the National Hospital examination showed severe bilateral wasting of the quadriceps and less pronounced wasting of the glutei and hamstrings. She was unable to lift her legs off the bed and only a flicker of contraction was detected in the quadriceps. There was marked weakness of the glutei and hamstrings. Slight weakness of dorsiflexion and eversion at the left ankle were present, power being normal on the right. The knee jerks were absent and the ankle jerks depressed. The plantar responses were extensor. Sensory testing showed impairment to 
touch and pin-prick over the left little finger and below both knees. She was unable to stand or walk.

Electrical studies showed denervation (sustained fibrillation) in both ulnar and median supplied muscles in the right hand without slowing of motor conduction velocity (median nerve $46 \mathrm{~m} / \mathrm{sec}$; ulnar nerve $50 \mathrm{~m} / \mathrm{sec}$ ). No sensory action potential could be recorded from either the median or ulnar nerve at the wrist. There was gross denervation of both quadriceps with profuse fibrillation and no muscle units under voluntary control. Conduction velocity in the median popliteal nerve was calculated to be $31 \mathrm{~m} / \mathrm{sec}$.

In the ward diabetic control was good and she became mobile.

At follow-up three years later she was receiving tolbutamide and was on a diet. Her diabetes was under close supervision and control had remained good with most urines sugar-free. On examination she was able to walk 100 metres using calipers and two sticks. Wasting and weakness of small hand muscles were present and, in addition, some more generalized weakness in the right arm. In the legs there was less severe wasting than before and she was now able to lift each leg off the bed for 10 seconds. There was bilateral weakness of all muscle groups of moderate degree. No tendon jerks were elicitable. The plantar responses were flexor. Sensory testing showed impairment to all modalities in the right thumb and index finger and to pin-prick, touch, and vibration below the knees.

Comment.-Muscle wasting and weakness developed during a period of loss of diabetic control. Improvement followed reinstitution of good diabetic control but at follow-up there was still a serious degree of disability.

\section{Discussion}

These cases closely resemble those described by Garland. Pain was common, and the motor deficit often profound with asymmetrical proximal lower limb wasting and weakness. Diabetic patients may develop wasting and weakness confined to the quadriceps with sensory change in the thigh, indicating a lesion of the femoral nerve in isolation (Goodman, 1954; Calverley and Mulder, 1960). In some of these cases the femoral neuropathy is considered to be part of a diabetic mononeuritis multiplex, other individual peripheral nerves-for example, the ulnar nerve-also being affected. However, none of the present patients had wasting or weakness restricted to the quadriceps, and none had the characteristic sensory loss, so a simple femoral neuropathy must be regarded as distinct from the syndrome under discussion.

The clinical evidence further suggests that there may be an associated cord lesion, at least in some of the patients. Thus, both in the present and in Garland's series there were patients in whom an extensor plantar response was regularly obtained. In some of Garland's patients, and in one of ours, the plantar response became flexor during treatment. It is thus unlikely that the original extensor plantar responses had been due to unrelated conditions such as cervical spondylosis or cerebrovascular disease.

The exact nature of the neurological lesion is still not decided. Electromyographic and muscle biopsy studies have shown that the muscle wasting and weakness are neurogenic and not myopathic. Nerve biopsy specimens in two patients who had sufficient proximal weakness to justify a diagnosis of diabetic amyotrophy showed the histological changes of segmental demyelination and axonal degeneration (Thomas and Lascelles, 1966). The marked slowing of conduction velocity in peripheral nerves in some patients suggests that the dominant pathological process may be the demyelination (Chopra, Hurwitz, and Montgomery, 1969; Thomas, 1971).

The rapidity and completeness of the recovery of muscle bulk and power in many of the cases are too great to be explained by reinnervation by axonal collateral sprouting and suggest that the nerve lesion in diabetic amyotrophy is reversible.
Raff, Sangalong, and Asbury (1968) found infarction of nerve fascicles in a single case and argued that the syndrome was vascular in origin. The fact that recovery is common and can be complete suggests that no infarction of peripheral nerve occurs. Further, the relation of the neurological syndrome to the control of the diabetes, and in particular its recovery after diabetic control, points more to a metabolic process.

This follow-up study has confirmed that improvement is usual and can sometimes result in complete reversal of muscle wasting and weakness. Significant functional disability may persist, however, in a proportion of cases.

The evidence from our patients also supports the belief that the development of this form of neuropathy, and its prognosis, are influenced by the degree of control of the blood sugar. In drawing such conclusions it is important to acknowledge the difficulties in assessing diabetic control, particularly in retrospect. Nevertheless, the diabetic control in our patients, preceding the onset of the amyotrophy, had often been less than satisfactory, a conclusion which seemed to be confirmed by the subsequent need to intensify the treatment in most of the patients to achieve good control.

After changes in the diabetic management some degree of recovery of the neurological syndrome was the rule. In one patient (Case 4), in whom control was satisfactory only over an initial inpatient period of observation, neurological improvement occurred only during that period. This patient was alone in failing to achieve persistently good diabetic control, and was the only one with no neurological recovery over the long term.

Although much remains to be discovered about the pathogenesis of this particular form of diabetic neuropathy, it seems clear that its natural history is closely related to the diabetic metabolic disturbance. It has been difficult to establish a close relation between the outlook of other, basically vascular, complications of diabetes and the degree of therapeutic control (Bloom, 1967), and therefore this syndrome is of 'special interest. It also means that once diabetic amyotrophy is diagnosed attempts should be made to establish rigid diabetic control.

It is a pleasure to express our gratitude to Professor $\mathbf{R}$. W. Gilliatt for his advice and encouragement. We are also indebted to Dr. M. Kremer and Dr. W. Ian McDonald for allowing us to study patients under their care and to Dr. R. G. Willison for helpful discussions and for details of electrodiagnostic studies.

\section{References}

Bloom, A. (1967). Proceedings of the Royal Society of Medicine, 60, 149. Calverley, J., and Mulder, D. W. (1960). Neurology, 10, 963. Chopra, J. S., Hurwitz, L. J., and Montgomery, D. A. D. (1969). Brain, 92, 391.

Fry, I. K., Hardwick, C., and Scott, G. W. (1962). Guy's Hospital Reports,

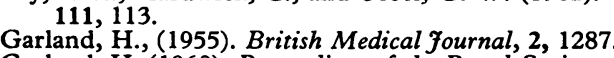

Garland, H. (1960). Proceedings of the Royal Society of Medicine, 53, 137

Garland, H., and Taverner, D. (1953). British Medical fournal, 1, 1405.

Gilliatt, R. W. (1965). In Biochemical Aspects of Neurological Disorders, ed. J. N. Cumings and M. Kremer, 2nd series. London, Blackwell, Scientific.

Gilliatt, R. W., Goodman, H. V., and Willison, R. G. (1961). Fournal of Neurology, Neurosurgery and Psychiatry, 24, 305.

Gilliatt, R. W., and Sears, T. A. (1958). Fournal of Neurology, Neurosurgery and Psychiatry, 21, 109.

Gilliatt, R. W., and Willison, R. G. (1962). Fournal of Neurology, Neurosurgery and Psychiatry, 25, 11.

Goodman, J. I. (1954). Diabetes, 3, 266

Goodman, J. I. (1954). Diabetes, 3, 266. S. (1953). The Diabetic Neuropathies. Springfield, Illinois, Thomas.

Hamilton, C. R., Dobson, H. L., and Marshall, J. (1968). American fournal of the Medical Sciences, 256, 81.

Raff, M. C., Sangalong, V., and Asbury, A. K. (1968). Archives of Neurology, 18,487 .

Redwood, D. R. (1962). British Medical fournal, 2, 521.

Sullivan, J. F. (1958). Neurology, 8, 243.

Thomas, P. K. (1971). Proceedings of the Royal Society of Medicine, 64, 295.

Thomas, P. K., and Lascelles, R. G. (1966). Quarterly fournal of Medicine, $35,489$.

Thomas, P. K., Sears, T. A., and Gilliatt, R. W. (1959). Fournal of Neurology, Neurnsurgery and Psychiatry, 22, 175. 